\title{
Vulnerability and Risk Assessment of Interdependent Tourism Actor Networks in Crisis Situations (Case Study Tangier, Morocco-COVID-19)
}

\author{
Rachdi Youssef, El Felsoufi Zoubir, Bernoussi Abdes Samed \\ EMMC, Faculty of Science and Technology, Tangier, Morocco \\ Email: yousefrachdi@gmail.com
}

How to cite this paper: Youssef, R., Zoubir, El F., \& Samed, B. A. (2022). Vulnerability and Risk Assessment of Interdependent Tourism Actor Networks in Crisis Situations (Case Study Tangier, Morocco-COVID-19). Open Journal of Business and Management, 10, 424-439.

https://doi.org/10.4236/ojbm.2022.101025

Received: December 3, 2021

Accepted: January 24, 2022

Published: January 27, 2022

Copyright $\odot 2022$ by author(s) and Scientific Research Publishing Inc. This work is licensed under the Creative Commons Attribution International License (CC BY 4.0).

http://creativecommons.org/licenses/by/4.0/

\begin{abstract}
This paper presents an analysis of tourism networks, and by defining the concepts of actor-networks and critical actors, an approach to modeling interdependent actor networks is presented, with the aim of assessing the influences and risks that can arise between actors. The approach is based on Graph Theory. It is our contribution to carry out a modeling to present the networks of actors with the inter-actor influences with a view to measuring the vulnerability index for each actor in crisis situations (case of COVID-19). For this purpose, an approach was adopted, which consisted of several stages including qualitative and quantitative analysis. A case study of the city of Tangier in the northern region of Morocco is presented in this paper.
\end{abstract}

\section{Keywords}

Tourism Actor, Vulnerability, Network, Risk, COVID-19

\section{Introduction}

The contribution of several actors to the development of the tourism sector and the collaboration between them is indispensable to achieving this objective. However, it is possible for this development to be influenced and slowed down by the dysfunction of one or more members of the network of actors owing to an internal (conflicts, professionalism, quality, etc.) or an external risk (climatic hazards, epidemics, natural hazards, hygiene, political or violent social events, etc.).

Several research studies have been carried out which support the fact that col- 
laboration between different actors is an essential factor for the development of the tourism sector (Cole, 2006; Giauque \& Gaillard, 2006; Timur \& Getz, 2008; Wray, 2011; Luloff, 2010; Choi \& Murray, 2010). So, it is apparent that the previous works explicitly address the notion of interdependency of actors but not to the extent that is relevant to our issue (notably the matter of vulnerability of interdependent actors in crisis situations).

Therefore, the aim of this paper is to propose a methodology for assessing the vulnerability and risk of tourism networks in an uncertain environment, taking into account the interdependencies between actors.

To achieve this aim, the key concepts are defined and the assessment methodology is specified, starting with a contextual mapping, regarded as a crucial step in setting the boundaries of the networks to be assessed. After having carried out a functional analysis to identify the specificities of the operation due to the interdependencies, a modelling method is proposed for this purpose, capable of being integrated into the Graph theory. Subsequently, we explored how to take into account the influences of the operating environment on the resulting model. The last part of this paper presents the vulnerability and risk model and concludes with an implementation case on the city of Tangier.

\section{The Tourism Chain and the Different Actors}

The tourism sector is composed of several actors and stakeholders in a configuration in which no actor functions separately, but in a complex web of interactions with other actors, thus giving rise to the notion of networks. Several authors among them we mention the following: (Oliver \& Jenkins, 2003; Bousset et al., 2007; Cawley, 2007; Clark \& Chabrel, 2007; Saxena et al., 2007) have addressed the notion of networks as a key phase in the success of the tourism sector.

\subsection{Networks of Actors}

The concept of actor-networks is regarded in a number of works in tourism as an important factor. The term refers to a grouping of actors whose purpose is to "provide access to information, seek, obtain and share resources, cooperate for mutual benefit, develop a collective vision, disseminate ideas and mobilize resources" (Saxena et al., 2007: p. 354). Some other authors see actor networks as a "third track" that links the local to the extra-local and the public to the private (Cawley, 2007: p. 408).

\subsection{Actors and Critical Players}

The actor is a strategic thinker and has room for action. He/she develops and implements strategic games within the framework of relationships (collaboration, alliance, confrontation, opposition, negotiation, etc.) in order to achieve his/her objectives. Thus, Hatem (1993) defines him as a person, a group, or an organization, aiming at certain objectives and faced with certain constraints, and 
who can, through his/her strategies and means of action influence the future of the studied system. In the same context and According to Godet (1997), an actor is a homogeneous group having common objectives and means of action, implementing the same strategy and displaying a balance of power in relation to other actors.

An actor can be regarded as mission-critical, his/her failure or dysfunction leads to an unacceptable risk and loss of essential performance.

\subsection{Insight into the Existing Network of Actors: Problem and Analysis}

The existence of a multitude of actors may not be a problem in and of itself, but the type and nature of the partnerships forged may be so. Owing to the interdependencies of these actors, the dysfunction of one actor, which can be called critical, is likely to spread to the others, on a scale that can exceed that of a region or a country, which raises the problem of vulnerability assessment.

To solve this problem and in order to limit the threatening components as much as possible to reduce the risks in due time, the methodology adopted for the approach to this problem is as follows:

* Understanding the relationships between the different actors and stakeholders in the tourism value chain.

* Modelling the functioning of networks in the tourism sector.

* Studying the interdependencies of the actors.

- Estimating the vulnerability of actors.

* Introducing probability for risk estimation.

\section{Approach to the Problem}

Any stakeholder can be subject to uncertainties, more or less high internal and external disturbances, which causes a dysfunction of the actors' networks in the absence of a proactive approach represented in the assessment of the vulnerability of the actors towards these uncertain events.

\subsection{Assessment of Crisis Situations}

It nevertheless happens that certain unusual situations caused by internal or external disturbances to the networks, lead to a weakening of the networks and a change in crisis, damaging the safety of people, economic activity, the environment, and properties. These situations can be experienced in several types of aliases that can be categorized into the following groups: Flood, Volcano, Fire, Earthquake, and Tsunami.

It is important to mention that the first measure of crisis communication is the assessment of the crisis situation, in most cases, it is not necessary to analyze the crisis situations for all actors, the interdependency matrix developed by the experts quantifies the conditional probability that situation $\mathrm{X}$ will occur knowing that situation $\mathrm{Y}$ has taken place. The conditional probability and impact of the 
crisis are obtained by combining criteria (probability of occurrence, intensity, duration of action, speed of execution, number and detectability of precursors, extent, lag time between signs and event, mitigating events, environment). These techniques, such as Morkov's, can be used to assess the probability of the crisis situation:

$$
P\left(E_{s}\right)=\sum_{0}^{T} P\left(E_{x} \mid E_{y}\right) P\left(E_{y}\right)
$$

$E_{X}, E_{Y}$. correspond to crisis situations.

$P\left(E_{s}\right)$ : corresponds to the conditional probability.

The next step is to identify the networks of actors likely to be affected by these hazards. In some cases, the hazards identified affect only certain actors.

\subsection{Identifying the Networks of Actors}

The actors operate in a concrete network of actions that concerns the maintenance of the structure through regulatory mechanisms. This construct, Bernoux (2014) confirms, is both stable and often informal, but never completed, allowing actors to establish transactions necessary to maintain and continue action in difficult situations. The first obstacle that analysts face is the selection of relevant networks.

In a comprehensive manner, there are seven categories of A.N, which represent the seven National Federations of Tourism Professions in Morocco:

* Transport (Aerial, Maritime, Terrestrial...),

* Tour operators (Travel agency, Reservation platform, TO...),

* Institutional actors (The Ministry of Tourism, The National Office of Tourism, The Regional Councils of Tourism...),

* Local actors (Craftsmen, Bazaar merchants, Cooperatives...),

* Accommodation facilities (Hotels, Inns, Bivouac Gîtes, Riad),

* Leisure facilities (Club, activities, experiences...),

* Tourist Restaurants.

\subsection{Functional Analysis}

Functional analysis is an intuitive approach that enables search, prioritization, evaluation, formulation, characterization, and valorization of the service functions offered by an actor or network of actors to meet the needs. Before modeling, it allows the identification of the actors involved in an interdependency. It must include at least the following steps:

* Definition of the real and functional tree structure of networks and sub-networks.

* Identification of the service functions.

* Identification of the elements and resources allowing realizing these functions.

* Definition of the constraint functions of the flows circulating between the actors as well as of the actions necessary to their good functioning. 
The functional analysis is what facilitates the representation and modeling of the network in the following section.

\subsection{Network Modeling}

Modeling is a real representation for the purpose of analysis; this representation can be mathematical or graphic. It makes it possible to evaluate the impact of the hazards. Modeling by graph theory, results in a graph composed of vertices and edges. For example, in a transport system, the vertices are the stations and the edges are the routes.

Based on this theory, we can model any network of actors by a set of vertices and edges, the types of vertices correspond to the actors involved, so a vertex can be a function performed in the network, this function can be: Produce, Relay, Use (Petit, Robert, \& Rouselle 2004; Jönsson \& Johansson, 2008); to which we add Process and Transport when it is a cessation. This modeling will remain partial as long as we do not integrate the interdependencies because, in case of a conflict between the types of vertices, the priority is given to the type of the principal flow, this flow can be obtained by the functional analysis of the concerned vertex. In the following part, we deal with the modeling of the interdependencies.

\subsection{Modeling Interdependencies}

In any network, the actors are not only dependent on each other but also on their environment. Interdependence is a link between two actors, this latter can be functional or represent a constraint; these dependencies are the main cause of decreased performance in the network of actors and place analysts in a situation of radical doubt or ignorance (Rinaldi, Peerenboom, \& Kelly, 2001).

The main difficulty in modeling networks is therefore to take into account the dependencies between actors.

To model interdependencies one must identify the following five types of links:

\begin{tabular}{cc}
\hline Type of link & Description \\
\hline input & When one actor provides another \\
Mutual dependency & Service is in both directions \\
The co-location & Both are located in the same region \\
Sharing & When they have a common resource \\
The Or-exclusive & When only one service is provided at a given time \\
\hline
\end{tabular}

In this paper, sharing, input and mutual dependency symbolize the same link, only the actor and the direction of the flow vary. Moreover, the co-location and the exclusive OR are also the same; so, they symbolize what we call an influence.

By recognizing the state of the actors and the direction of the flows, we will be 
able to model all types of links either by a dependency or by an influence. To do so, we will explain the approach in the sections below.

\subsubsection{Dependency}

The edge between two vertices represents a dependency; this latter is essential if the flow transported by the edge is a main flow. Generally speaking, $S_{1}$ depends on $S_{2}$ if there is a flow from $S_{2}$ to $S_{1}$. This link is incorporated into the network structure as shown in Figure 1.

\subsubsection{Influence}

An actor $S_{2}$ is geographically dependent on an actor $S_{1}\left(S_{1}\right.$ influences $\left.S_{2}\right)$ if there is no functional link between the two actors but a failure of $S 1$ leads to a failure of $S_{2}$. We symbolize an influence by an edge (dotted line) of zero weight and carrying no flow.

The two types of links determined operate between the actors of the network (edges and vertices). We have chosen to model the network using Graph's theory, and we present in the following lines how to integrate these links into a network represented by a weighted and oriented graph.

\subsubsection{Vertex-Vertex Type}

Between two vertices, we find different types of links that can be either a dependency or an influence. For (Johansson \& Hassel, 2010) among others, they symbolize the dependency between two vertices by an edge, this kind is oriented like the other edges, so if the vertex $S_{2}$ depends functionally on the vertex $S_{1}$, we symbolize this dependency by an edge starting from $S_{1}$ to $S_{2}$. However, a dotted edge symbolizes the influence of $A_{2}$ on $A_{1}$ (see Figure 2).

An influence can exist between vertices of the same type (the disappearance of a tour operator leading to an influence on another one), or between vertices of different types (the cessation of an airline decreasing the lodging occupancy rate of the accommodation facilities). On the other hand, standard edges represent the dependency between two vertices of the same type; however, the dependency between vertices of the same kind does not exist.

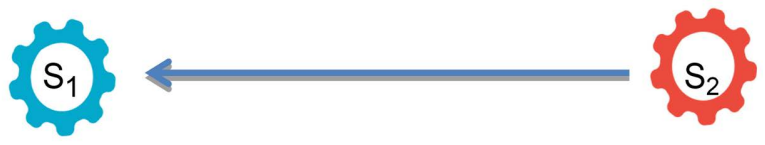

Figure 1. Dependency edge. Source: Author's compilation.
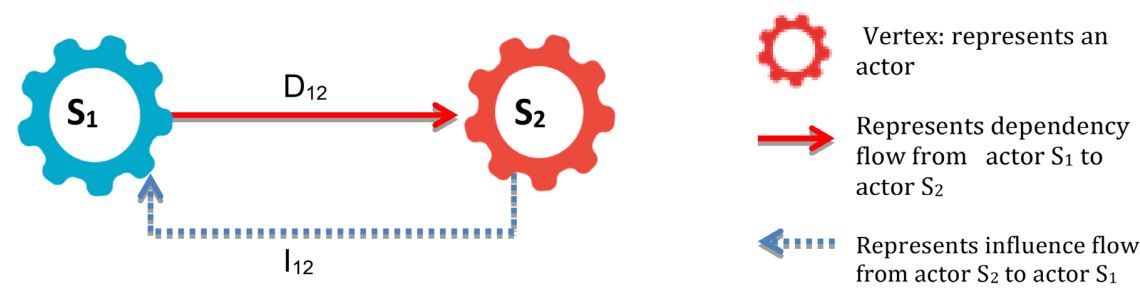

Figure 2. The link between two vertices. Source: Author's compilation. 


\subsubsection{Vertex-Edge Type}

We only speak of a link between the vertices, sometimes in certain situations, a tour proposed by a travel agency and provided by a tourist transport, can be disrupted (for example: a case of a poisoning due to an unscheduled meal in a tourist restaurant) surely affects the whole tour. To model the dependency of an edge $A$ on a vertex $S$, we introduce a virtual edge $A^{\prime}$ of zero weight and a virtual vertex S' of infinite capacity. The failure probabilities of the virtual elements $S^{\prime}$ and $\mathrm{A}^{\prime}$ are zero and a virtual edge is an instance of one and only one real edge, see (Figure 3).

\subsubsection{Edge-Vertex Type}

Let us now assume that it is the vertex V3 that depends on edge $\mathrm{E}$, this is the example of a tour operator that has stopped sending tourists (change of destination) to a travel agency, a decision that will have repercussions on the tour guides of this destination. This type of link is modeled in Figure 4.
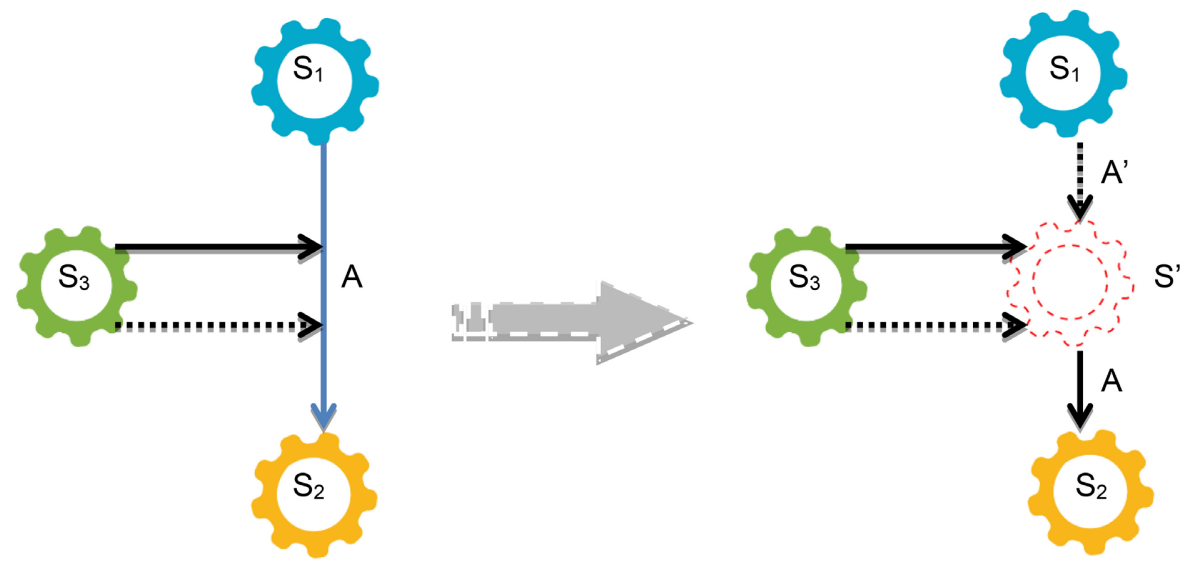

$S_{i}$ Vertex represents an actor i $\mid \mathbf{A}^{\prime}$ virtual edge of zero weight $\mid \mathbf{S}^{\prime}$ virtual vertex

Figure 3. Vertex-edge link type. Source: Author's compilation.
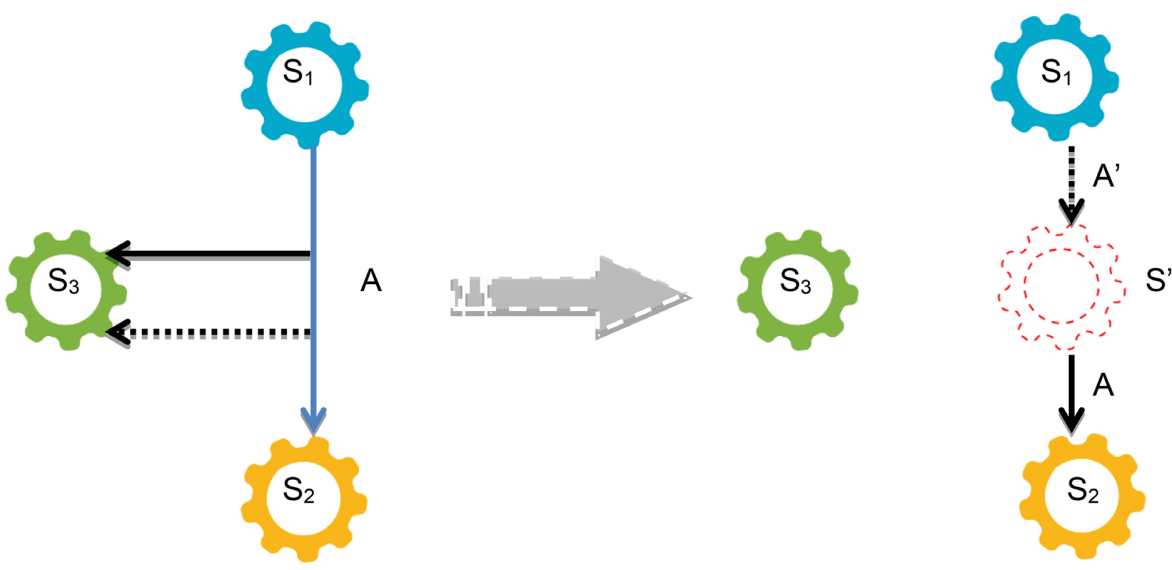

$\mathrm{S}_{\mathrm{i}}$ Vertex represents an actor i | A' virtual edge of zero weight | S' virtual vertex

Figure 4. Edge-vertex type of link. Source: Author's compilation. 


\subsubsection{Edge-Edge Type}

As far as the dependencies and influences between the edges are concerned, they are profoundly linked from a functional point of view, e.g. between the Tour guides and the restaurants, and the modeling of this link can be presented in Figure 5.

Up until now, we have considered the effects of the actors themselves, but the environment in which it operates can also affect the functioning of an actor. We illustrate in the following, an approach to cover this influence.

\subsubsection{Modelling the Influence of the Components of the External Environment}

Various elements are part of the composition of the external environment, which makes the triggers for an actor's dysfunction more numerous. For this reason, and in order to identify these possible causes, an analysis method is used which allows the possible sources of the cause to be detected, this is what we call the diagram of Ishikawa, which is based on the classification of the various causes into 5 major categories: Material, Environment, Methods, Equipment, and Manpower. In our case study:

* Matter: represents the different flows circulating in the networks, with their characteristics (processing time, clauses and contracts), the fluidity of the different flows in the network is a vulnerability indicator;

* Environment: represents the space within which the activity takes place, its appearance, its physical organization, it may be a defined perimeter;

* Methods: these are procedures or measures followed to carry out the activity, they can be information flows or regulations of trade;

* Material: this is the equipment, systems, machines, and tools;

* Manpower: these are the human resources, certificates, expected qualifications, ...

In Figure 6, each actor is characterized by a dysfunction, Moreover; the edges are endowed with weight functions.
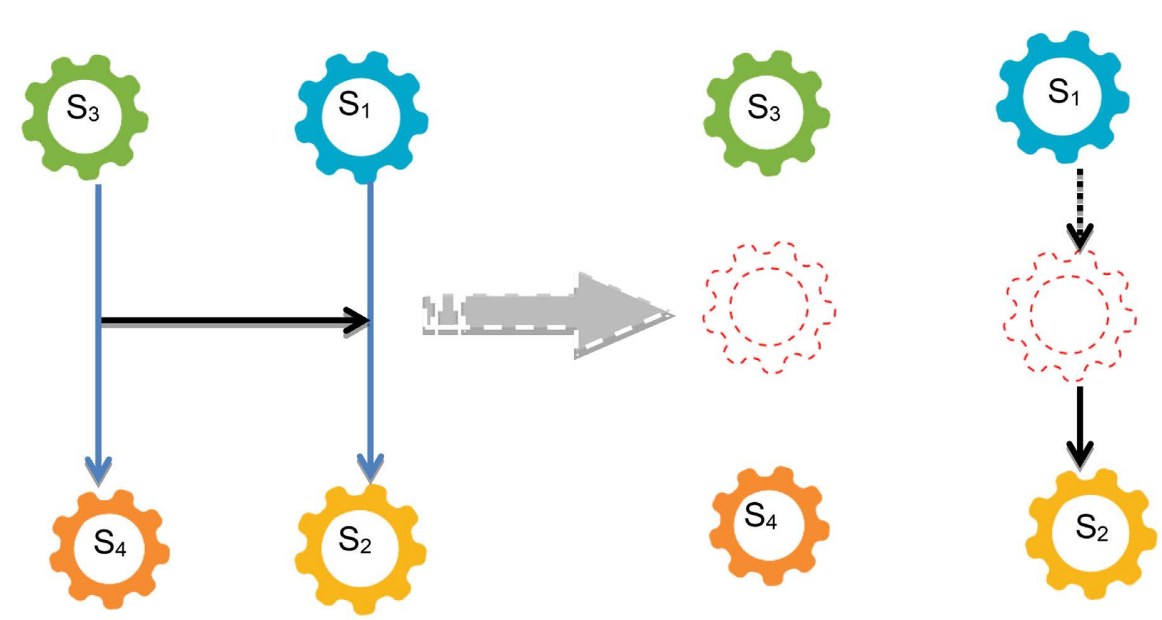

Figure 5. Type of edge-edge link. Source: Author's compilation. 


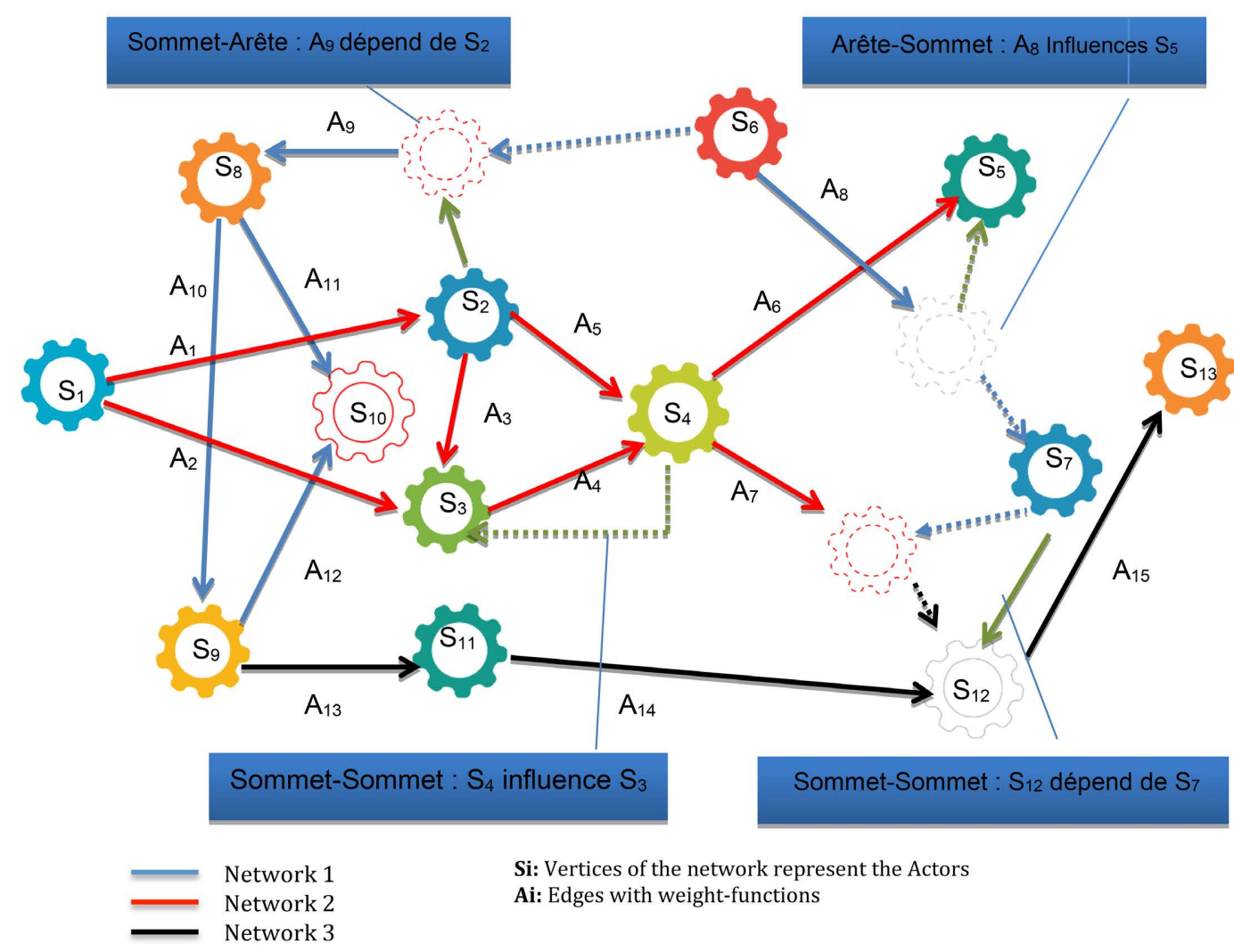

Figure 6. Example of a multi-network interdependent model. Source: Author's compilation.

\subsubsection{Estimation of Vulnerability}

Vulnerability is seen as a reference to everything that favors the dysfunction of an issue or damage to the interest of the actors. The notion of vulnerability is the subject of multiple definitions and broad debates (Becerra \& Peltier, 2009). However, beyond its general definition, the problem that arises in practice is to measure this vulnerability. In order to do this, some authors agree on the properties of vulnerability, the most highlighted ones are cited here:

* The vulnerability index is a function between 0 and 1 .

* The vulnerability should not increase by adding edges.

* In different networks of the same size, the complete graph is the least vulnerable.

* Vulnerability is related to several parameters, it is multidimensional.

* Path redundancy and the presence of complementary networks that can transport the same elements reduce vulnerability.

In the light of these assumptions, and in order to estimate this vulnerability, we first analyze the effect of a given disturbance on the network (or certain network actors). To this end, we consider the states of the network before and after the crisis, which are noted respectively as $\boldsymbol{E}_{\boldsymbol{i}}$ (initial state before the crisis) and $\boldsymbol{E}_{\boldsymbol{f}}$ in the presence of the crisis. These two states can represent, for example, revenues or profits. Thus if $E_{f}>E_{i}$, we can say that the presence of disturbance is beneficial for the system but if $E_{f}<E_{i}$ then the disturbance is harmful. In the 
first case, the network is not vulnerable, whereas in the second case it is. An example is the impact of COVID-19 on the economic fabric of a country or region: some sectors may suffer but others may proliferate. In this case, we get the following definition:

Definition: We say that a network actor (or the network) is vulnerable to disturbance only if $E_{f}<E_{i}$.

Remark: In this definition the duration of time $=] 0, T$, (time between the beginning and the end of the crisis (disturbance)) is important. So we should take $E_{i}\left(t_{0}=0\right)$ and $E_{f}(t)$, for $t$ in $I$. In this study, we consider only the initial and final instants $T$. In future studies, we will consider in detail the impact of time (duration of the crisis).

We can therefore quantify the degree of vulnerability and estimate its index as follows:

$$
I_{V}=\frac{E_{i}-E_{f}}{E_{i}}
$$

$E_{f}$ represents the final state of the network after the occurrence of the crisis situation.

$E_{i}$ is the initial state of the network before the occurrence of the crisis situation.

The vulnerability of the networks thus depends on the relative importance of the flows, the structural and functional importance of the source vertices and the vertices reached, and the type of vertex that fails (Jönsson \& Johansson, 2008).

\subsubsection{Estimation of Risk}

A risk can be classified according to its degree of predictability, i.e. the probability of having negative consequences at a given moment under specified conditions, as explained earlier, the risk is a function of vulnerability, and the decrease of one leads to the decrease of the other. As a result, the analysis of vulnerability and risk are hardly dissociable and decisions are often made that reduce both. In general, risk management aims at answering a number of questions (Agarwal, Blockly, \& Woodman, 2003), summed up in these three:

* What can be done?

* What are the options available and what are the associated trade-offs in terms of costs, risks, and benefits?

* What are the impacts of management decisions on future policy options?

Risk is generally considered as an entity with two dimensions, probability on the one hand and consequences on the other (Leroy \& Signoret, 1992). We evaluate it by:

$$
\text { Ris }=P(A) \times I_{v} \times C
$$

$P(A)$ : The probability of the risk of actor $A$

$C$ : Consequences

$E_{f}$ The final state after the occurrence 
$E_{i}$ : The initial state of the network before the occurrence

This estimation only takes into account the risk that is inseparable from the networks considered with respect to crisis situations.

\section{Case Study of the City of Tangier for the Case of COVID-19}

\subsection{Presentation of the City of Tangier (Map)}

Tangier is a city located between two maritime sides (Mediterranean and Atlantic), in the Strait of Gibraltar, in the north of Morocco, and has long been a favorite destination for artists and intellectuals. According to statistics published by the Moroccan Tourism Observatory in 2019, Tangier is one of the most attractive destinations in the country, as it is located only 14 kilometers from Spain and also because of its African roots mixed with Spanish, Portuguese, and French influences which makes it a fascinating city. Tourists of all ages come here to wander through its narrow streets, admire its old medina and enjoy its beautiful coastline. For this reason, we have selected it as a field of implementation, in which we have chosen two different types of travel agencies, a hotel, a tourist transport company, a guide, and a restaurant as the actors involved.

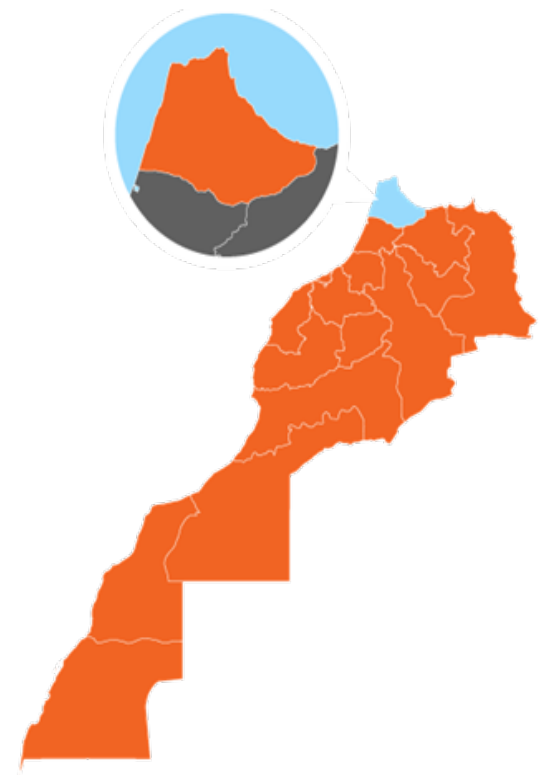

\subsection{Implementation}

In the context of this implementation, we will focus on private actors, whose revenues will be used as an observation indicator, which represents the sum of the company's sales of products or services, i.e. the amount (excluding tax) of all transactions carried out by the actor with third parties in the context of its normal and current activity. For the confidential nature of this indicator, but also for the purpose of obtaining detailed data, the values presented will be in percentages. The sources used to have these values are The National Confederation of Tourism and Regional Association of Travel Agencies of Tangier-Tétouan-Al 
Hoceima of which we are members.

We first present the modeling of the relationships between the different actors in our implementation, and then we show the revenue per actor before and during the COVID-19 crisis.

\subsection{Analysis and Interpretation of the Results}

Table 1: represents the revenues achieved between each of the two actors before the existence of COVID-19, the said figure affirms the model of Figure 7 , and where a value of $0 \%$ in the cell that connects two actors, indicates that there is no dependency (no direct link, example Agency 1 and Agency 2). On the other hand, a value other than $0 \%$ shows that there is interdependency and that the rate represents the degree of the relationship (example Hotel and Agency 1).

Table 2: represents the revenues achieved in 2020 after the period of total containment, but still in a period of crisis, as the borders remained closed, which brought us to a total halt in the activity of the airlines, thus negatively influencing the actors that are in relation with it, as shown in Figure 7.

In terms of revenues, it can be observed that the crisis has had an impact on all inter-actor transactions. The cessation of the airline's activity is reflected in a null revenue, which has also influenced the revenue of the other actors according to their degree of interdependency.

The travel agency is also the only actor that is in contact with almost all other actors, it plays the role of service aggregator.

The type of this actor (Agency) determines the actors that can be in collaboration. In our implementation, we find two types of agencies:

Agency 1: is an incoming travel agency, it welcomes, organizes excursions, stays, and tours in the city for foreigners and organizes Hajj and Omra (Pilgrimage) trips for Moroccans (Table 3).
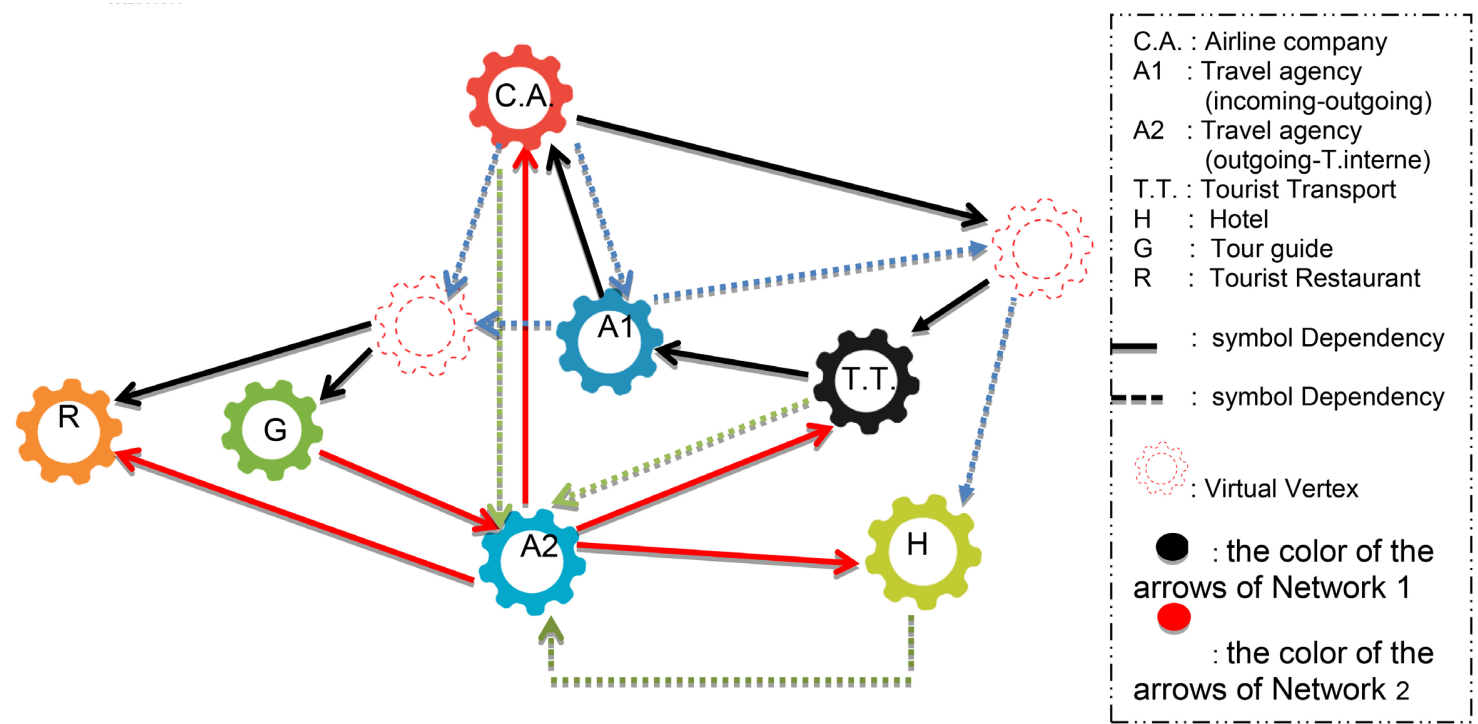

Figure 7: Links between the actors involved in the implementation process. Source: Author's compilation 
Table 1. Revenues in 2019 between selected actors (before COVID-19).

\begin{tabular}{|c|c|c|c|c|c|c|c|}
\hline & Agency 1 & Agency 2 & Hotel & Tourist transport & Tour guide & Restaurant & Airline company \\
\hline $\begin{array}{c}\text { Agencyl (incoming \& } \\
\text { Hajj-Omra) }\end{array}$ & - & $0 \%$ & $6.3 \%$ & $8.7 \%$ & $2.1 \%$ & $5 \%$ & $27 \%$ \\
\hline $\begin{array}{l}\text { Agency2 (outgoing \& } \\
\text { domestic tourism) }\end{array}$ & $0 \%$ & - & $5 \%$ & $13 \%$ & $3 \%$ & $4 \%$ & $21 \%$ \\
\hline Hotel & $6.3 \%$ & $5 \%$ & - & $0.1 \%$ & $0 \%$ & $0 \%$ & $0.0 \%$ \\
\hline Tourist transport & $8.7 \%$ & $13 \%$ & $0.1 \%$ & - & $0 \%$ & $0 \%$ & $0.01 \%$ \\
\hline Tour guide & $2.1 \%$ & $3 \%$ & $0 \%$ & $0 \%$ & - & $0 \%$ & $0 \%$ \\
\hline Restaurant & $5 \%$ & $4 \%$ & $0 \%$ & $0 \%$ & $0 \%$ & - & $0 \%$ \\
\hline Airline company & $27 \%$ & $21 \%$ & $0 \%$ & $0.01 \%$ & $0 \%$ & $0 \%$ & - \\
\hline
\end{tabular}

Table 2. Revenues in 2020 between selected actors (during COVID-19).

\begin{tabular}{|c|c|c|c|c|c|c|c|}
\hline & Agency 1 & Agency 2 & Hotel & Tourist transport & Tour guide & Restaurant & Airline company \\
\hline $\begin{array}{c}\text { Agency } 1 \text { (incoming \& } \\
\text { Hajj-Omra) }\end{array}$ & - & $0 \%$ & $0 \%$ & $0 \%$ & $0 \%$ & $0 \%$ & $0 \%$ \\
\hline $\begin{array}{c}\text { Agence } 2 \text { (outgoing \& } \\
\text { domestic tourism) }\end{array}$ & $0 \%$ & - & $2 \%$ & $6 \%$ & $0.5 \%$ & $1 \%$ & $0 \%$ \\
\hline Hotel & $0 \%$ & $2 \%$ & - & $0 \%$ & $0 \%$ & $0 \%$ & $0 \%$ \\
\hline Tourist transport & $0 \%$ & $6 \%$ & $0 \%$ & - & $0 \%$ & $0 \%$ & $0 \%$ \\
\hline Tour guide & $0 \%$ & $0.5 \%$ & $0 \%$ & $0 \%$ & - & $0 \%$ & $0 \%$ \\
\hline Restaurant & $0 \%$ & $1 \%$ & $0 \%$ & $0 \%$ & $0 \%$ & - & $0 \%$ \\
\hline Airline company & $0 \%$ & $0 \%$ & $0 \%$ & $0 \%$ & $0 \%$ & $0 \%$ & - \\
\hline
\end{tabular}

Table 3. Agency 1 vulnerability index per actor.

\begin{tabular}{cccc}
\hline Agency 1: & Before $\left(E_{i}\right)$ & After $\left(E_{f}\right)$ & $V_{i}$ (Vulnerability Index) \\
\hline Hotel & $6.3 \%$ & $0 \%$ & 1 \\
Tourist transport & $8.7 \%$ & $0 \%$ & 1 \\
Tour guide & $2.1 \%$ & $0 \%$ & 1 \\
Restaurant & $5 \%$ & $0 \%$ & 1 \\
Airline company & $27 \%$ & $0 \%$ & 1 \\
\hline
\end{tabular}

Agency 2: it works on internal and outgoing tourism (making Moroccans travel abroad) (Table 4).

The third column of each table represents the vulnerability index per actor, which can be calculated via the following relationship:

$$
I_{V}=1-\frac{E_{f}}{E_{i}}
$$

The numbers obtained show that Agency 2 is less vulnerable than Agency 1, 
Table 4. Agency 2 vulnerability index per actor.

\begin{tabular}{cccc}
\hline Agency 2: & before $\left(E_{i}\right)$ & After $\left(E_{f}\right)$ & $V_{i}$ (Vulnerability index) \\
\hline Hotel & $5 \%$ & $2 \%$ & 0.6 \\
Tourist transport & $13 \%$ & $6 \%$ & 0.54 \\
Tour guide & $3 \%$ & $0.5 \%$ & 0.83 \\
Restaurant & $4 \%$ & $1 \%$ & 0.75 \\
Airline company & $21 \%$ & $0 \%$ & 0 \\
\hline
\end{tabular}

because, despite the crisis situation, it has achieved a small revenue from internal tourism, which has had a positive impact on the revenue of the other actors in the network. On the other hand, agency 1 is proved to be extremely vulnerable.

In the light of this analysis, it can be concluded that the assessment of the vulnerability of an actor can only be estimated through the analysis of interdependencies with other components of the network, including the external components.

\section{Conclusion}

Of course, the tourism industry has been in difficulty before, but the COVID-19 pandemic has greatly exacerbated these difficulties and has had strong economic and social impacts on its development. In general hazards are troublesome events for the tourism sector; through the intermediary of networks, they can affect a large number of actors and lead to a crisis situation, during this situation any decision must be aimed at resisting, adapting and finding a new stable position close to the initial one after the occurrence of the hazard. For this purpose, and before the decision is taken, a formalization of the problem is necessary.

In this paper, the first objective was to propose a model and to come up with a way to present the networks in a general sense with the following constraint: this model must integrate the interdependencies as well as the influence of the external environment. The second objective was to model the risk through vulnerability.

The different types of interdependencies were identified and a model compatible with graph theory was proposed, as well as an approach for estimating vulnerability and risk.

Through the model proposed in this work, we can deduce, among others, the unpredictable and potentially damaging scenarios, the critical actors, the states of vulnerability of the network, the influence of each network on the other networks, etc. It should be noted that our next line of study will be the use of cognitive agents for crisis management.

\section{Conflicts of Interest}

The authors declare no conflicts of interest regarding the publication of this paper. 


\section{References}

Agarwal, J., Blockley, D., \& Woodman, N. (2003). Vulnerability of Structural Systems. Structural Safety, 25, 263-286. https://doi.org/10.1016/S0167-4730(02)00068-1

Becerra, S., \& Peltier, A. (2009). Risques et environnement: Recherches interdisciplinaires sur la vulnérabilité des sociétés.

Bernoux, P. (2014). The Sociology of Organizations: Theoretical Introduction Followed by Twelve Practical Cases. Points.

Bousset, J.-P. et al. (2007). A Decision Support System for Integrated Tourism Development: Rethinking Tourism Policies and Management Strategies. Tourism Geographies, 9, 387-404. https://doi.org/10.1080/14616680701647576

Cawley, M., \& Gillmor, D. A. (2007). Integrated Rural Tourism: Concepts and Practice. Annals of Tourism Research, 35, 316-337. https://doi.org/10.1016/j.annals.2007.07.011

Choi, H. C., \& Murray, I. (2010). Resident Attitudes toward Sustainable Community Tourism. Journal of Sustainable Tourism, 18, 575-594. https://doi.org/10.1080/09669580903524852

Clark, G., \& Chabrel, M. (2007). Measuring Integrated Rural Tourism. Tourism Geographies, 9, 371-386. https://doi.org/10.1080/14616680701647550

Cole, S. (2006). Information and Empowerment: The Keys to Achieving Sustainable Tourism. Journal of Sustainable Tourism, 14, 629-644. https://doi.org/10.2167/jost607.0

Giauque, D., \& Gaillard, T. (2006). Partenariat entre secteurs public, privé et associative: Une affaire de valeurs et d'adhésion. Revue économique et sociale, 2, 53-73.

Godet, M. (1997). Manuel de Prospective stratégique. Dunod.

Hatem, F. (1993). La prospective. Pratiques et Méthodes.

Johansson, J., \& Hassel, H. (2010). An Approach for Modelling Interdependent Infrastructures in the Context of Vulnerability Analysis. Reliability Engineering \& System Safety, 95, 1335-1344. https://doi.org/10.1016/j.ress.2010.06.010

Jönsson, H., \& Johansson, J. (2008). Identifying Critical Components in Technical Infrastructure Networks. Proceedings of the Innsttution of Mechanical Enginners, Part $O$ : Journal of Risk and Reliability, 222, 235-243. https://doi.org/10.1243/1748006XJRR138

Leroy, A., \& Signoret, J.-P. (1992). Le risque technologique. Que sais-je 2669. Presses Universitaire de France (PUF).

Luloff, A. E. (2010). Community Agency and Sustainable Tourism Development: The Case of La Fortuna, Costa Rica. Journal of Sustainable Tourism, 18, 735-756. https://doi.org/10.1080/09669581003653526

Oliver, T., \& Jenkins, T. (2003). Sustaining Rural Landscapes: The Role of Integrated Tourism. Landscape Research, 28, 293-307. https://doi.org/10.1080/01426390306516

Petit, F., Robert, B., \& Rousselle, J. (2004). Une nouvelle approche pour la caractérisation des aléas et l'évaluation des vulnérabilités des réseaux de support à la vie. Canadian Journal of Civil Engineering, 31, 333-344. https://doi.org/10.1139/104-008

Rinaldi, S. M., Peerenboom, J. P., \& Kelly, T. K. (2001). Identifying, Understanding, and Analyzing Critical Infrastructure Interdependencies. Control Systems, 21, 11-25. https://doi.org/10.1109/37.969131

Saxena, G., Clark, G., Oliver, T., \& Ilbery, B. (2007). Conceptualising Integrated Rural Tourism. Tourism Geographies, 9, 354-370. https://doi.org/10.1080/14616680701647527 
Timur, S., \& Getz, D. (2008). A Network Perspective on Managing Actors for Sustainable Urban Tourism. International Journal of Contemporary Hospitality Management, 20, 445-461. https://doi.org/10.1108/09596110810873543

Wray, M. (2011). Adopting and Implementing a Transactive Approach to Sustainable Tourism Planning: Translating Theory into Practice. Journal of Sustainable Tourism, 19, 605-627. https://doi.org/10.1080/09669582.2011.566928 